\title{
Linking static and dynamic mechanical properties for metamorphic rocks from Austria including their anisotropic effect
}

\author{
Nina Gegenhuber ${ }^{1} \cdot$ Melanie Krueger $^{1}$
}

Received: 16 October 2020 / Accepted: 3 March 2021 / Published online: 20 March 2021

(c) The Author(s) 2021

\begin{abstract}
The derivation of geomechanical properties from petrophysical/geophysical data is not only of great importance in the oil industry but also in mining, geothermal projects and tunnelling, for reduction of costs and to improve security. For the oil industry and geothermal sector, it is mainly important for drilling rate and the stability of the borehole and, as a result, the economic factor. A key issue is that geomechanical properties, which can support a better planning of a project, cannot be measured in the borehole or on the surface directly. In this study, the focus is put on anisotropic effects on the correlation between static and dynamic properties, which is neglected in most studies but important because values can vary extremely. Therefore, measurements in the geotechnical laboratory of compressional and shear wave velocity during uniaxial compression strength test were taken. Additionally, typical properties like bulk and grain density as well as porosity were determined too. Different samples (carbonate-silica schist, marble and phyllite) from the "Zentrum am Berg"-research tunnelling centre at the "Erzberg" in Austria were used. Shown are correlations between uniaxial compression strength and compressional wave velocity as well as for static and dynamic Young's modulus including their anisotropic effect. The results are promising and provide an opportunity for further applications on log data.
\end{abstract}

Keywords Static Young's modulus · Dynamic Young's modulus · Correlations · Uniaxial compression strength · Anisotropy

\section{Introduction}

The derivation of geomechanical properties from petrophysical/geophysical data is not only of great importance in mining but also in geothermal projects, in geotechnics and in tunnelling or the oil industry. These data can, for example, help within the tunnel excavation and as result optimize technologies, reduce costs and improve security. For the oil industry and the geothermal sector, it is mainly important for drilling rate and the stability of the borehole (e.g. Mody et al. 2008; Nes et al. 2005; Nygard et al. 2007) and as a result the economic factor. The problem is that most relevant geomechanical properties (static elastic moduli, strength

Communicated by Michal Malinowski (CO-EDITOR-INCHIEF)/Jadwiga Anna Jarzyna, prof (ASSOCIATE EDITOR).

Nina Gegenhuber

nina.gegenhuber@unileoben.ac.at

1 Montanuniversitaet Leoben, Erzherzog-Johann Strasse 3, 8700 Leoben, Austria properties especially uniaxial compression strength (UCS)) cannot be only very difficult and expensive but also cannot be measured in the borehole or on the surface directly, but only in laboratories on rock samples. This also gives just an idea of rock strength in the field itself, because it is just a point information.

Many studies focus on the correlation between uniaxial compression strength and various petrophysical properties like compressional or shear wave velocity, density, porosity and water content for different rock types, which can be found countless in the literature. Chen and $\mathrm{Hu}$ (2001) presented data for weak sandstones, Oyler et al. (2008) show sonic travel time versus UCS for coal measure rocks, and Jabbar (2011) shows the correlation not only between UCS and compressional wave velocity $\left(\mathrm{v}_{\mathrm{p}}\right)$, but also points load test, including influencing factors like water content. None of them take mineralogical or pore space anisotropy into account.

Altindag (2012) summarized in his paper empirical equations from various papers for the correlation between $v_{p}$ and UCS for different rock types. Additionally, he presents an 
own set of data and correlations for sedimentary rock types. Same was done by Karami et al. (2012) where literature equations are presented and further data by themselves for a water convey tunnel (limestone samples) are shown. Chang et al. (2006) gave 31 equations summarized from the literature. A first good overview for geomechanical properties in the oil industry is given in the book of Fjaer et al. (2008), which covers physical backgrounds, measuring methods, models, correlations and applications of geomechanical properties. A compilation of empirical relationships was published by Schoen (2015) or Horsrund (2001).

Most papers focusing on anisotropy of UCS never use it to correlate the data with petrophysical data. They present anisotropy data with varying UCS in different directions and the description of these effects (e.g. Ajalloeian and Lashkaripour 2000; Nasseri et al. 2003; Karakul et al. 2010; Sroglou et al. 2004; Buhiyan et al. 2013). Al-Harthi (1998) measured UCS and compressional wave velocity in $15^{\circ}$ steps of varying directions on sandstone samples, but did not put those in relationship to each other for a correlation.

Other papers focus on the prediction from geomechanical properties from well-log data, like Tokle at el. (1986); Butel et al. (2014) or Memarian (2006). Correlations of dynamic and static Young's modulus are presented by van Heerden (1987) or Najibi et al. (2015). Jiang and Sun (2011) published the relationship between static and dynamic properties for Xishan Rock Cliff Statue.

In this study, the focus is put on anisotropic effects on the correlation between static and dynamic properties. This is neglected in most studies, but important because values can vary extremely as you can see in the result section. Therefore, measurements in the geotechnical laboratory of compressional $\left(\mathrm{v}_{\mathrm{p}}\right)$ and shear $\left(\mathrm{v}_{\mathrm{s}}\right)$ wave velocity during uniaxial compression strength test were taken. Different samples (carbonate-silica schist, marble and phyllite) from the "Zentrum am Berg"-research tunnelling centre at the "Erzberg" in Austria (http://www.zab.at/) were used.

Shown are correlations between uniaxial compression strength and compressional wave velocity as well as for static and dynamic Young's modulus including the anisotropic effect. The resulting equations give the opportunity for further applications on well-log data.

\section{Samples and methods}

\section{Samples}

Samples were taken in the new research tunnels at the "Erzberg" (Austria) during the excavation with blasting and digger. A first set of measurements on these samples were conducted in the laboratory. These data and results presented here will be used also in follow-up projects, with focus on better exploration and followed by a better excavation for tunnels. Selected lithologies are carbonate-silica schist, marble and phyllite. Smaller specimens are drilled in the geotechnical laboratory at the Montanuniversitaet Leoben from the big samples from the tunnel excavation. Two sets of samples have been used: (a) length: $2.5 \mathrm{~cm}$ and diameter $5 \mathrm{~cm}$ for compressional and shear wave velocity, bulk and grain density and effective porosity and (b) length: $10 \mathrm{~cm}$ diameter: $5 \mathrm{~cm}$ for compressional and shear wave velocity during UCS. The sample set (a) was saturated overnight $(12 \mathrm{~h})$ in a brine ( $1 \mathrm{~g} \mathrm{NaCl}$ and 11 distilled water) for the measurements of $v_{p}$ and $v_{s}$ and the determination of effective porosity with the principle of Archimedes. Sample set (b) were not saturated for these geotechnical experiments. For the measurements in different directions, if an anisotropy was visible, samples are drilled normal and perpendicular to schistosity (Fig. 1) to deliver minimum and maximum values. There are different sources of anisotropy; in this case, it was simplified to a two-axial anisotropy. Two rock types were selected according to the geological description where both of them cover set (a) and (b) samples.

Rock type 1 in the study area includes pebble slate with transitions into a limestone silicate rock or even limestone marble. The carbonate silica rock shows up to $\mathrm{cm}$-large carbonate bulbs (anchorite, siderite) and a high quartz content. It is fine-grained, indistinctly banky or slate to massive with light to dark grey colour. The predominantly mediumsized fissures healed with quartz, calcite or dolomite. The dividing surfaces are mostly flat and rough and sometimes silty. The strength of the rock is high, locally very high. The strength is partially reduced due to the tectonic stress and small-scale folding. Locally, there is also light grey to dirty white, fine-grained marble, which appears thin-banked to banked, but mostly appears rather massive. Fissure areas

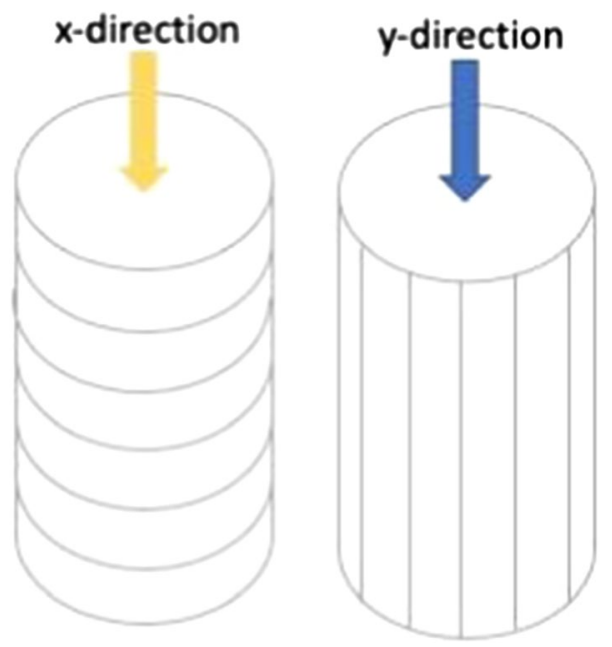

Fig. 1 Basic principle of sample preparation: normal and perpendicular to schistosity drilled 
are mostly closed, but also show mm-to-cm-thick calcite fillings, locally also with iron oxide. Partitions are silty in some areas. Shale and fracture areas are only mechanically effective.

Lithologies of rock type 2 occurring in the study area are carbonate-silica rocks and phyllite. The carbonate-silica rocks are grey, dark and greenish grey pebble schist with activated lime bulbs, which are also referred to as quartzitic slate. This shows an alternating bearing made of sericite quartz slate and chlorite quartz slate, some of which are carbonate. The slates are thin-banked to platy and fissured. Slate surfaces are pronounced; dividing surfaces are flat or wavy to smooth. Both dividing and slate areas are often silty and sericitic. Fissures have healed in the mm-to-cm range and mostly with quartz or calcite/dolomite. Phyllite is also quartzitic slate to quartzite phyllite, which is thin-banked, subordinate plate-shaped. The rock is severely to moderately disassembled and fractured. Most of the slate surfaces are flat to smooth, and partitions are often covered with silt or sericite.

Both lithologies were strongly tectonically overprinted and sometimes intensely folded. They show moderately high

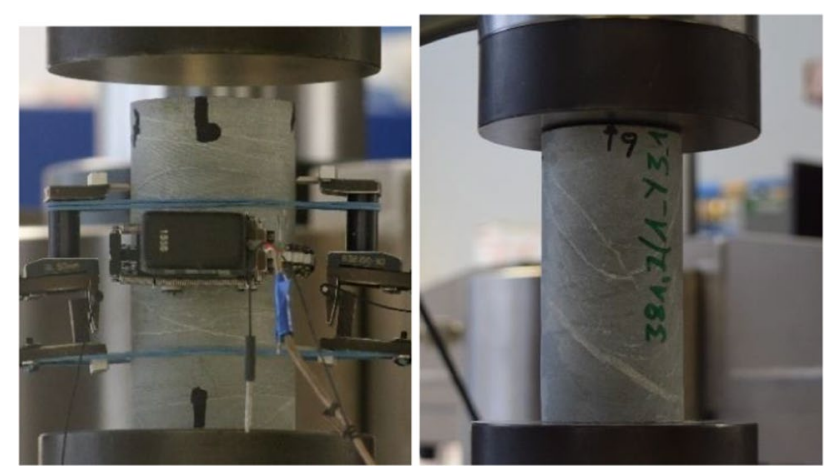

Fig. 2 One selected rock sample: phyllite, normal and perpendicular to schistosity drilled to high rock strengths. The nature of the dividing surfaces increases the partial mobility of individual fracture bodies. The anisotropies, which can be seen in the data especially for the phyllite, are often not proper evenly layers, but often metamorphic bent (Fig. 2 right).

Table 1 gives the minimum and maximum values of the first selected samples at tunnel meter from 370 to $440 \mathrm{~m}$ for compressional and shear wave velocity dry, bulk density, grain density and effective porosity, Young's modulus static and dynamic, uniaxial compression strength and shear and compressional modulus.

\section{Measuring method}

Compressional $\left(\mathrm{v}_{\mathrm{p}}\right)$ and shear wave $\left(\mathrm{v}_{\mathrm{s}}\right)$ velocity dry and brine saturated were measured first with an ultrasonic device on the smaller (diameter: $5 \mathrm{~cm}$, length: $2.5 \mathrm{~cm}$ ) set of prepared samples, additionally to the bigger ones for the geotechnical measurements. Bulk density was calculated with measured length, diameter and mass dry on these samples. Samples are thereafter dried overnight $(12 \mathrm{~h})$ at $105^{\circ} \mathrm{C}$. Porosity was calculated from grain density (measured with a helium pycnometer) and from measurements using the principal of Archimedes. The effective porosities from pycnometer were used, where data were available.

Additionally, compressional and shear wave velocities were measured during uniaxial compression strength test on selected bigger samples (diameter: $5 \mathrm{~cm}$, length: $10 \mathrm{~cm}$, Fig. 2). The machine-constructional part of the experimental set-up was planned in a way so probes from the company "Geotron Elektronik" (Pirna, Germany) were not exposed to the high forces during the uniaxial compression test. With this set-up, forces up to 2500 $\mathrm{kN}$ could be controlled (Pittino et al. 2015; Gegenhuber et al. 2017). A singular mechanical impulse having a frequency of $250 \mathrm{kHz}$ produced by a signal generator was sent through the sample. The arriving signal got
Table 1 Measured and calculated minimum and maximum data from the laboratory for the samples from 370 to 440 tunnel meters

\begin{tabular}{lllll}
\hline Parameter & Unit & Phyllite & Carbonate-silica schist & Marble \\
\hline Bulk density $(\rho)$ & {$\left[\mathrm{g} / \mathrm{cm}^{3}\right]$} & $2,69-2,81$ & $2,69-2,75$ & $2,65-2,77$ \\
Compressional wave velocity $\left(v_{P}\right)$ & {$[\mathrm{m} / \mathrm{s}]$} & $2908-7126$ & $3577-6321$ & $4838-6142$ \\
Shear wave velocity $\left(v_{S}\right)$ & {$[\mathrm{m} / \mathrm{s}]$} & $1835-4096$ & $2417-4463$ & $3257-3934$ \\
Shear modulus $(\mu)$ & {$[\mathrm{GPa}]$} & $9-46$ & $17-37$ & $13-42$ \\
Compressional modulus $(k)$ & {$[\mathrm{GPa}]$} & $11-92$ & $12-81$ & $23-68$ \\
Lamé-Konstante $(\lambda)$ & {$[\mathrm{GPa}]$} & $0,10-69,13$ & $0,07-66,54$ & $0,17-52,16$ \\
Young's modulus $\mathrm{E}_{\text {dyn }}$ & {$[\mathrm{GPa}]$} & $22-116$ & $35-93$ & $36-97$ \\
Poisson ratio dynamic & {[]} & $0,01-0,34$ & $0,01-0,33$ & $0,02-0,33$ \\
Grain density & {$\left[\mathrm{g} / \mathrm{cm}{ }^{3}\right]$} & $2,81-2,87$ & $2,81-2,82$ & $2,73-2,78$ \\
Effective porosity & {$[\%]$} & $0,5-1,9$ & $0,6-1,5$ & $0,9-1,5$ \\
Young's modulus $\mathrm{E}_{\text {stat }}$ & {$[\mathrm{GPa}]$} & $40-80$ & $36-63$ & $60-65$ \\
Uniaxial compression strength & {$[\mathrm{MPa}]$} & $105-171$ & $80-180$ & $34-171$ \\
\hline
\end{tabular}


forwarded to a storage oscilloscope and a computer. A self-made program (Gegenhuber and Steiner-Luckabauer 2012) detected the first arrival of the two wave modes and calculated the wave velocities $\left(\mathrm{v}_{\mathrm{p}}\right.$ and $\left.\mathrm{v}_{\mathrm{s}}\right)$ with the length of the specimen and including dead time. The dead time is the time of the signal through the probes without any sample.

For the measurements during the uniaxial compression strength test, a cylindrical rock sample was positioned between the two pressure plates, in which the probes were integrated. For an optimal result and uniform stress state, an additional spherical mounted pressure plate next to the fixed pressure plate was used. The sensors for the axial and radial changes were directly applied on the specimen. At the beginning, the specimen became loaded with a low axial pressure, and all sensors, except of the load cell, were adjusted. The following pressure stages were used and held for the required measuring time of $v_{p}$ and $v_{s}$. The presented $v_{p}$ and $v_{s}$ data are taken from the last measurement before the sample broke.

Figure 3 shows one example of measurement of $v_{p}$ and $\mathrm{v}_{\mathrm{p}} / \mathrm{v}_{\mathrm{s}}$ with the geomechanical cycle including loading and unloading at the beginning till the sample broke. At the beginning, always two loading and unloading cycles have been carried out for all these measurements. From $10 \mathrm{MPa}$ on, stress was increased into steps of $10 \mathrm{MPa}$ till the sample broke. To derive the static elastic modulus, at the beginning circumferential strain-controlled loops have been carried out with 5-20-5-30-5 MPa. Due to the fact that the material was so brittle, the loading values have been held low. Most of the material broke abruptly and was destroyed completely.

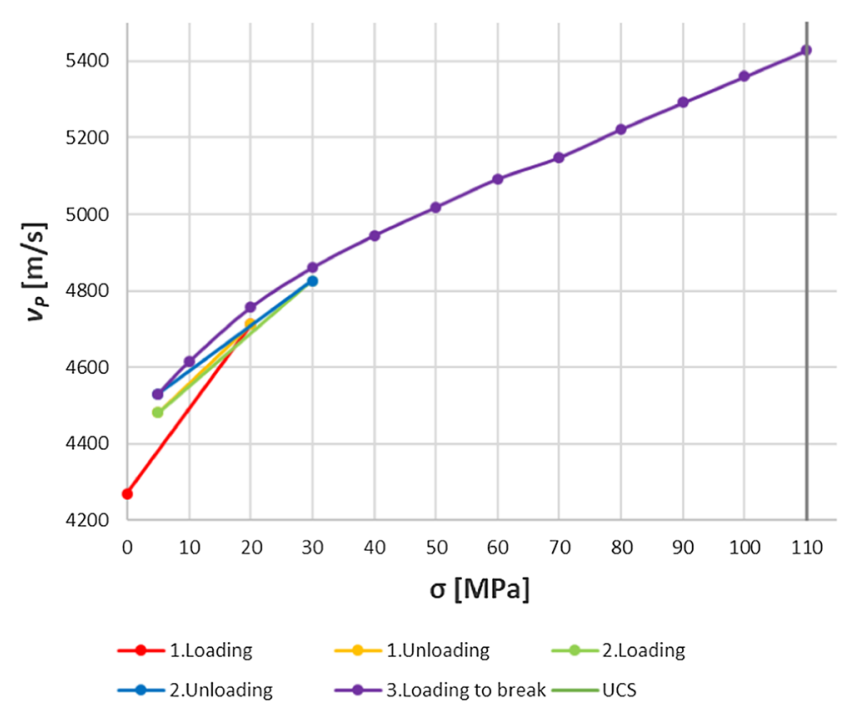

\section{Results and interpretation}

This section will give an overview on the different results including direct correlations between static and dynamic properties and a discussion on the influence of porosity and anisotropy for a better understanding of the results.

\section{(a) Relationship between $v_{p}, v_{s}$, porosity and bulk density}

First of all, the focus will be a petrophysical understanding of the samples. Therefore, Figure $4 \mathrm{a}$ and $\mathrm{b}$ shows $\mathrm{v}_{\mathrm{p}}$ and $\mathrm{v}_{\mathrm{s}}$ versus effective porosity (a) and bulk density (b). Data are grouped by lithology. As it can be seen, data do not scatter a lot and there is hardly any trend of increasing $v_{p}$ or $v_{s}$ versus increasing bulk density or effective porosity. These should be better visible, but this trend is "overlapped by the anisotropic effect".

One sample shows a slightly higher porosity value and does obvious not fit to the rest of the data set. This is a phyllite sample, which had a lot of cracks. The second sample, which does not fit properly, can be seen in the plot with density and shows lower bulk density than the rest. This is a carbonate-silica schist. The same sample, drilled in the other direction, does not show lower density. The other carbonate-silica-schist samples used for measurements (not UCS$\mathrm{v}_{\mathrm{p}} / \mathrm{v}_{\mathrm{s}}$, and therefore not shown here) show also slightly lower bulk density values than the phyllite samples. Scatter shows that for the rock types not only the porosity but also density controls $\mathrm{v}_{\mathrm{p}}$ and $\mathrm{v}_{\mathrm{s}}$. Probably also pore shape and orientation have an influence. Further studies carried out in the future could determine whether that this is the case.

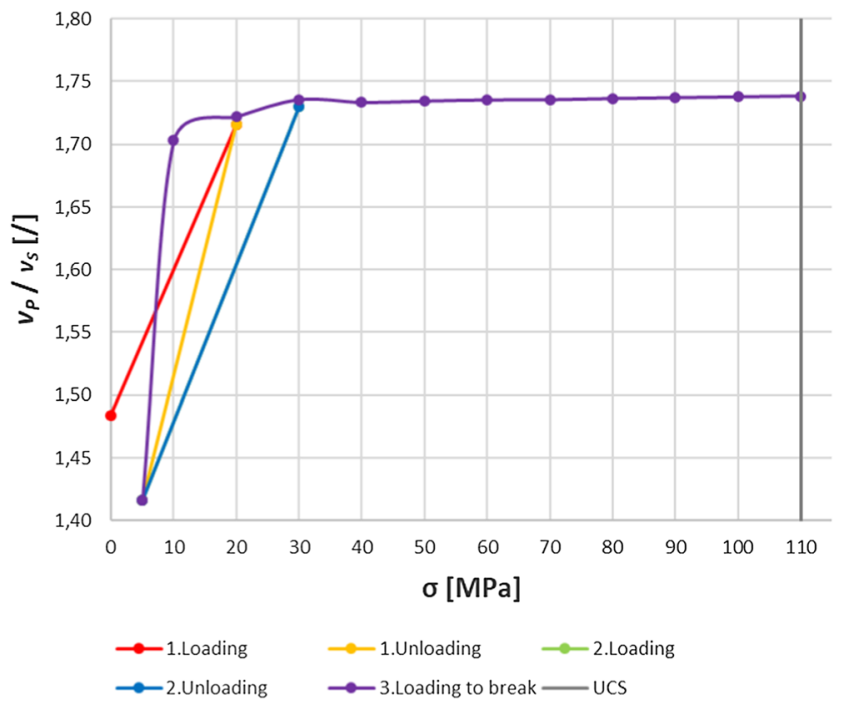

Fig. $3 v_{p}$ (right) and $v_{p} / v_{s}($ left) versus applied stress for one representative phyllite sample 

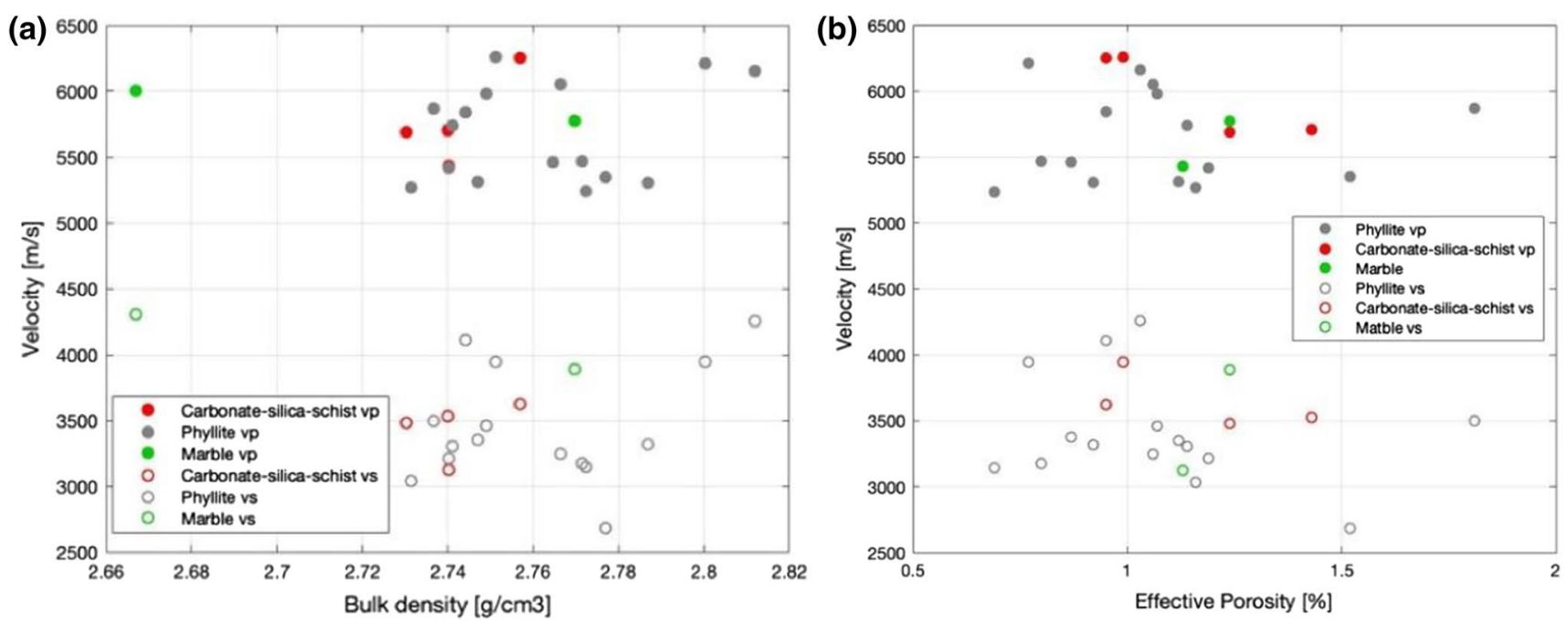

Fig. 4 Compressional and shear wave velocity dry a versus bulk density and $\mathbf{b}$ versus effective porosity, full circles show $\mathrm{v}_{\mathrm{p}}$, empty circles show $\mathrm{v}_{\mathrm{s}}$

\section{(b) Correlation between $v_{p}$ and UCS - the anisotropy influence}

Figure 5 shows the correlation between UCS and $\mathrm{v}_{\mathrm{p}}$. Data are grouped focusing on their directional dependence (Fig. 5b). The first approach of these correlations included a separation by lithology (Fig. 5a), which are important for correlations (e.g. Gegenhuber et al. 2017). The expected trend that $\mathrm{v}_{\mathrm{p}}$ increases when UCS increases can be observed. Compressional wave velocity in $x$-direction is higher than in $y$-direction in contrast to UCS data, which are lower in $y$-direction.

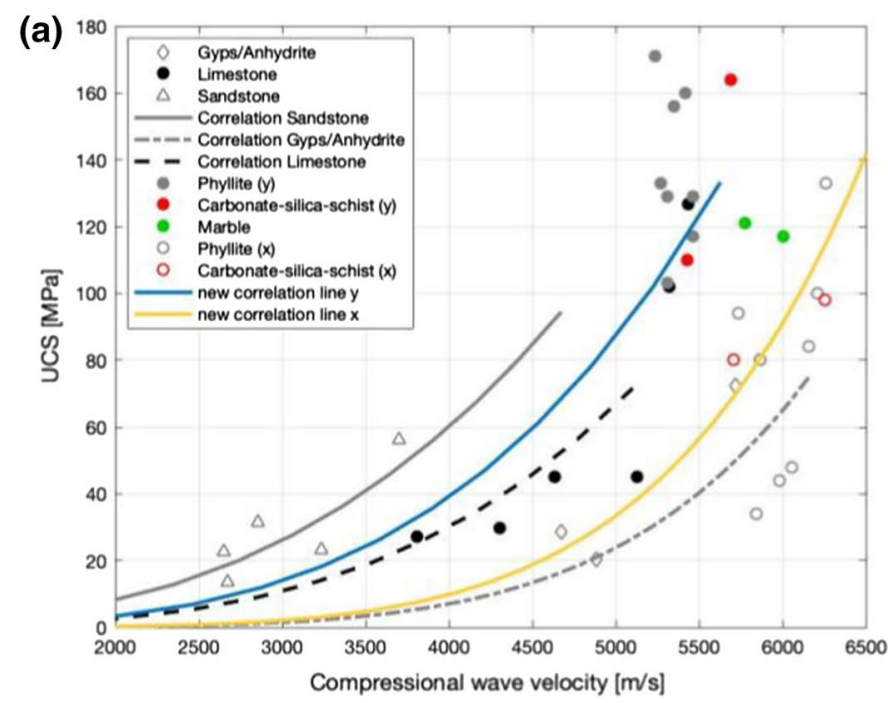

Fig. 5 a UCS versus compressional wave velocity, in yellow data in $x$-direction, in blue in $y$-direction, additionally shown are calculated correlation line, comparison including the previous data set (Gegen-
Correlation lines were derived the same way; then, it already worked well for our first set of data (Fig. 5a), where $\mathrm{v}_{\mathrm{p}}$ was calculated using Budiansky and O'Connell (1976) as inclusion model for low porous rocks. This approach was also applied on the correlation between compressional wave velocity and thermal conductivity for deriving a thermal conductivity log (Gegenhuber und Kienler 2017). Velocity values range between 5250 and $6300 \mathrm{~m} / \mathrm{s}$ in both directions and UCS from 40 to $180 \mathrm{MPa}$, a rather large range. Therefore again, it is important to take anisotropic effects into account for correlations between petrophysical and geotechnical properties.

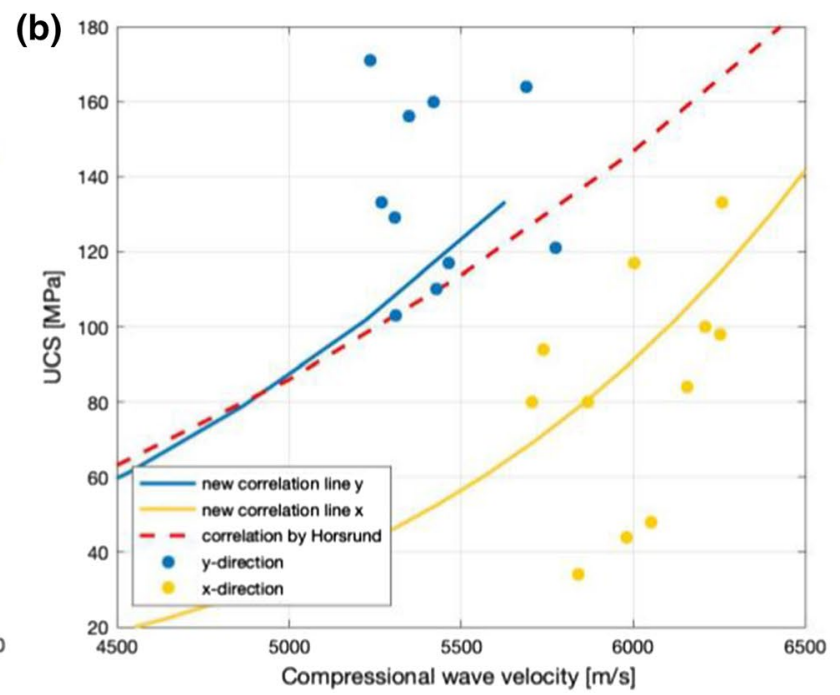

huber et al. 2017), b blue and yellow lines are the same than as Fig. 4 a and in red an additional correlation line from Horsrud (2001) is added 
Table 2 Correlation equations for uniaxial compression strength (UCS) and compressional wave velocity (vp) in the two derived directions $(x$ and $y$ ) for all lithologies as presented in Fig. $4 \mathrm{a}$ and $\mathrm{b}$

\begin{tabular}{ll}
\hline Correlation & Equation \\
\hline $\mathrm{UCS}-\mathrm{v}_{\mathrm{p}} x$-direction & $\mathrm{UCS}=4.2 \mathrm{E}-12 * \mathrm{v}_{\mathrm{p}}{ }^{\wedge} 3.6$ \\
$\mathrm{UCS}-\mathrm{v}_{\mathrm{p}} y$-direction & $\mathrm{UCS}=1.4 \mathrm{E}-19 * \mathrm{v}_{\mathrm{p}}{ }^{\wedge} 5.51$ \\
\hline
\end{tabular}

Anisotropy is essential for tunnel excavation, reservoirs and drilling.

The next step was to test different correlation equations for $v_{p}$ and UCS from the literature, due to the fact that UCS cannot be calculated with any inclusions model directly. Description of the empirical correlation between UCS and $\mathrm{v}_{\mathrm{p}}$ (or DTC) frequently uses a power law: $y=a x^{b}$ where $x$ is $\mathrm{v}_{\mathrm{p}}, y$ is UCS, coefficients a and $\mathrm{b}$ are empirical parameters. The derived equations are summarized in Table 2. We apply one equation for comparison: Horsrud (2001) derived for North Sea shale:

$\mathrm{UCS}=0.77 \cdot\left(\frac{\mathrm{v}_{\mathrm{p}}}{1000}\right)^{2.93}=1.25 \cdot 10^{-9} \cdot \mathrm{v}_{\mathrm{p}}^{2.93} R^{2}=0.99$

where UCS is in MPa and $\mathrm{v}_{\mathrm{p}}$ in $\mathrm{m} / \mathrm{s}$.

Figure 5a shows the correlation results for our previous set of data, where we had no anisotropic effects present and other rock types. Included are the new data from the "Erzberg" and two new correlation lines for the directional dependence. As it can be seen, there is no clear trend visible. Lithologies are mixed up in combination with the old dataset. Only the separation between $\mathrm{x}$ and $y$ direction is obvious. Some of the new data cannot be explained with the correlation equation. Figure $5 \mathrm{~b}$ shows additionally the correlation by Horsrud (2001), which support the data. Further data need to be included to strengthen the correlations. Specially the rock-type effect is probably not a driving factor in the correlation of $v_{p}$ and UCS than expected.

Further studies with more data are expected to support this theory, where lithology differences need to be considered and where other influences become more controlling. At the moment high limestone values from the study before, fit to the phyllite data in $y$-direction, whereas the correlation line of Gyps/Anhydrite fit to data in $x$-direction. As it can be seen, lithology influence is not that dominant in this dataset. Therefore, the anisotropy was used for a detailed analysis. Anisotropy, mineralogical or pore space is often neglected in correlation studies, but it is of great importance for drilling or casing, where the direction of the layers of rocks has a big influence. Drilling perpendicular or parallel to schistosity will have a big difference for the drilling rate.

\section{(C) Correlation between static and dynamic Young's modulus}

Further interpretation focusses on the correlation and understanding of static and dynamic Young's modulus with respect to anisotropy. Figure 5 shows the correlation between Young's modulus dynamic $\mathrm{E}_{\mathrm{dyn}}$ versus static $\mathrm{E}_{\text {stat }}$. Here only the correlation for the $x$-direction is presented. $Y$-direction did not deliver any good results for the correlation, as it can be seen in Fig. 6, nearly all $\mathrm{E}_{\text {stat }}$ values are located around $65 \mathrm{GPa}$. This is properly a result of the metamorphic influence on schistosity, where, as already seen and mentioned, layers are folded and not proper parallel to each other.

$\mathrm{E}_{\mathrm{dyn}}$ and $\mathrm{E}_{\text {stat }}$ have higher values in $y$-direction than in $x$-direction. Additionally presented is a comparison with an equation by King (1983), in: Schoen 2015) igneous and metamorphic rocks. The correlation line is similar to our derived correlation. Also, here the value range of dynamic and static Young's modulus is very high (30-70GPa for $\mathrm{E}_{\text {stat }}$ and 60 and 110GPa for $\mathrm{E}_{\mathrm{dyn}}$ ). In Table 3, all correlation equations for Young's modulus are summarized. These equations could further be applied on well-log data to derive static values from sonic log data, if direction of anisotropy is known.

For the correlation between $\mathrm{E}_{\mathrm{dyn}} / \mathrm{E}_{\text {stat }}$ and $\mathrm{E}_{\text {stat }}$, correlations in both directions fit well (Fig. 7). However, looking on regression coefficient (see Table 3), the correlation for $x$-direction is a better fit. In contrast, correlation of $\mathrm{E}_{\text {dyn }} / \mathrm{E}_{\text {stat }}$ and $\mathrm{E}_{\mathrm{dyn}}$ correlation of $y$-direction is the better one.

Again, the separation between the two directions is obvious. It can be assumed that especially for $y$-direction

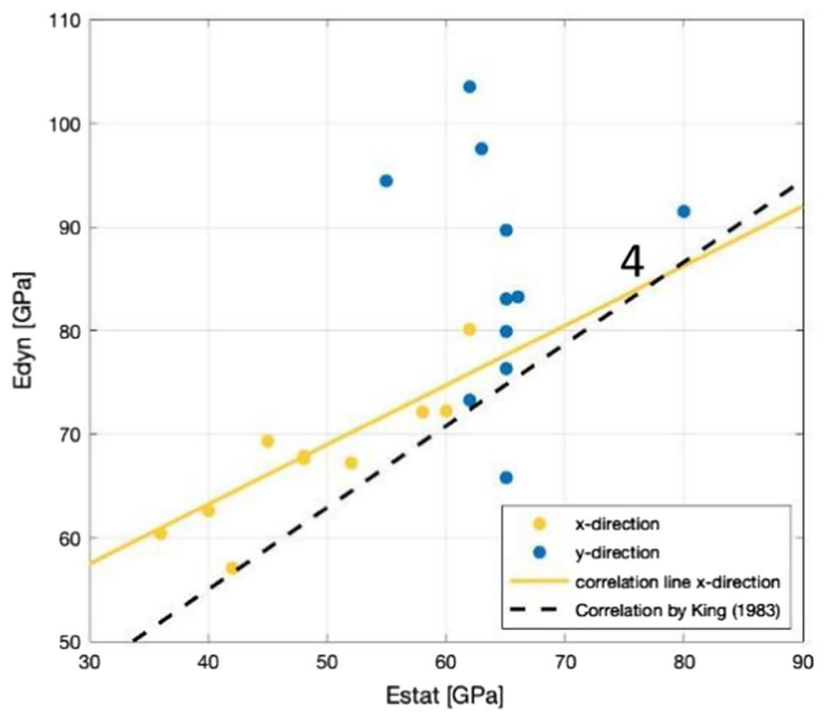

Fig. 6 Edyn versus Estat, correlation line only for $x$-direction, black line shows comparison with an equation by King (1983), in: Schoen 2015) 
Table 3 Correlation equations derived for static and dynamic Young's modulus

\begin{tabular}{llll}
\hline & Correlation & Equation & $R^{2}$ \\
\hline 1 & $\mathrm{E}_{\mathrm{dyn}} / \mathrm{E}_{\mathrm{stat}}-\mathrm{E}_{\mathrm{dyn}} x$-direction & $\mathrm{E}_{\mathrm{dyn}} / \mathrm{E}_{\mathrm{stat}}=2.211 * \mathrm{e}^{\wedge}-0.007 * \mathrm{E}_{\mathrm{dyn}}$ & 0.119 \\
2 & $\mathrm{E}_{\mathrm{dyn}} / \mathrm{E}_{\mathrm{stat}}-\mathrm{E}_{\mathrm{dyn}} y$-direction & $\mathrm{E}_{\mathrm{dyn}} / \mathrm{E}_{\mathrm{stat}}=0.444 * \mathrm{e}^{\wedge} 0.0127 * \mathrm{E}_{\mathrm{dyn}}$ & 0.737 \\
3 & $\mathrm{E}_{\mathrm{dyn}} / \mathrm{E}_{\mathrm{stat}}-\mathrm{E}_{\mathrm{stat}} x$-direction & $\mathrm{E}_{\mathrm{dyn}} / \mathrm{E}_{\mathrm{stat}}=13.882 * \mathrm{E}_{\mathrm{stat}}{ }^{\wedge}-0.59$ & 0.745 \\
4 & $\mathrm{E}_{\mathrm{dyn}}-\mathrm{E}_{\mathrm{stat}} x$-direction & $\mathrm{E}_{\mathrm{dyn}}=0.5754 * \mathrm{E}_{\mathrm{stat}}+40.198$ & 0.601 \\
\hline
\end{tabular}

Estat static Young's modulus, Edyn dynamic Young's modulus, $R^{2}$ regression coefficient
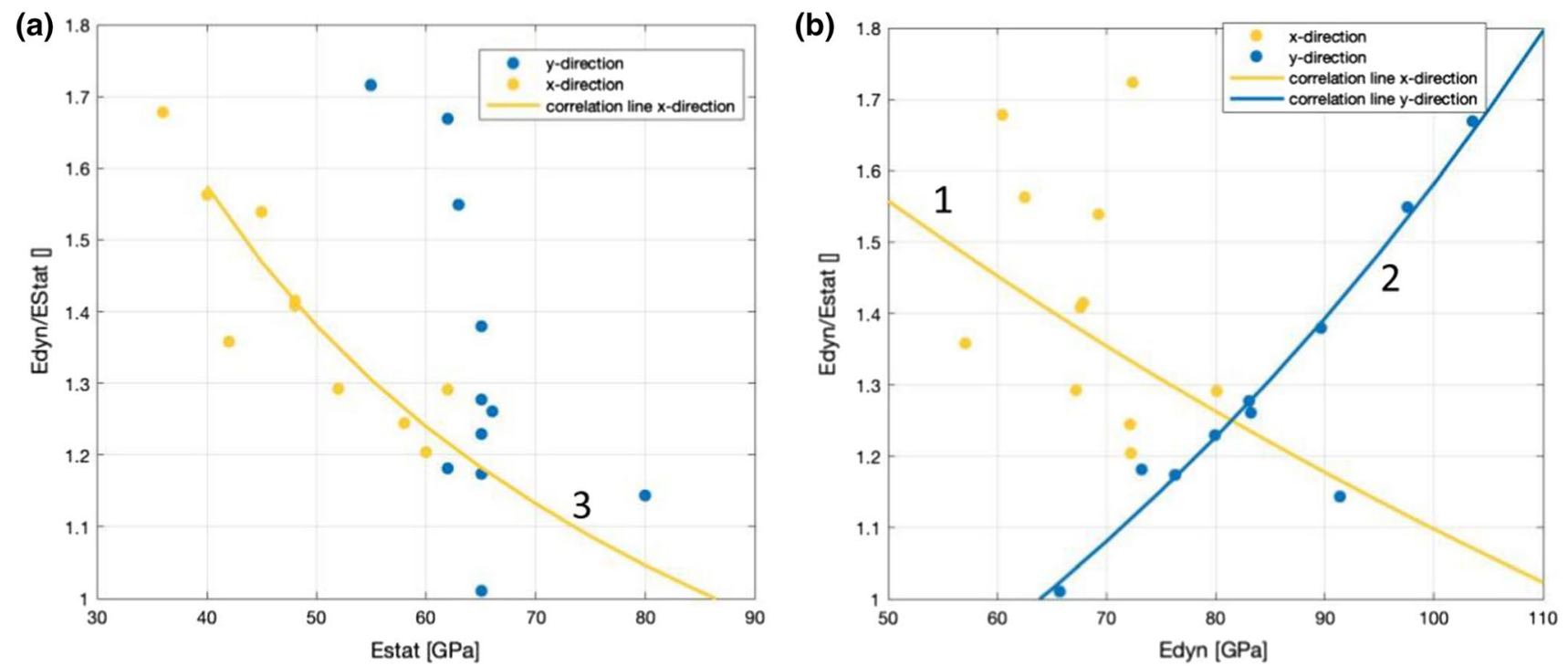

Fig. 7 Ratio of Edyn/Estat versus a Estat und b Edyn, color: yellow: $x$-direction, blue: $y$-direction, dots are measured values, lines are calculated correlations, numbers correlate with the equations can be found in Table 3

inhomogeneities are present because of the folding of the samples.

\section{Conclusion}

Correlations between geomechanical and petrophysical/ geophysical properties are of great interest, not only in mining and tunnelling but also in the oil industry, geothermal sector and hydrogeological fields. This paper addresses correlations of compressional wave velocity and uniaxial compression strength as well as dynamic and static Young's modulus including the understanding of anisotropic effects. Metamorphic samples from the "Erzberg" in Austria are used for these.

One main problem in $y$-direction is that schistosity is folded and no proper layers can be seen, which leads to some inhomogeneities and made the correlations difficult. Important is that anisotropic effects are although strongly visible and show that it is essential to take them into account.

The correlation between UCS and $v_{p}$ shows good results. The resulting equations can further be applied on well-log data, to derive geomechanical properties directly in the field. Velocity values range between 5250 and $6300 \mathrm{~m} / \mathrm{s}$ in both directions and UCS from 40 to $180 \mathrm{MPa}$, which is a big range.

The correlation between static and dynamic Young's modulus worked well in $x$-direction (normal to schistosity), but not in $y$-direction (parallel to schistosity). This behaviour is caused by different effects of inhomogeneities on the different physical measuring principle:

- Dynamic measurement with small stress magnitude and extremely short stress time application, static measurement with large stress magnitude and long time stress application;

- Dynamic response is controlled by elastic material properties but static by elastic and nonelastic.

The investigated rock types are anisotropic and inhomogeneous at various scales. We can conclude that the individual rock components and their orientation and shape affect dynamic and static measurements different; this difference-in our case-is very strong for the $y$-direction. Therefore again, it is important to take anisotropic effects 
into account for correlations between petrophysical and geotechnical properties.

Funding Open access funding provided by Montanuniversität Leoben.. This research did not receive any specific grant from funding agencies in the public, commercial, or not-for-profit sectors.

\section{Declarations}

Conflict of interest On behalf of all authors, the corresponding author states that there is no conflict of interest.

Open Access This article is licensed under a Creative Commons Attribution 4.0 International License, which permits use, sharing, adaptation, distribution and reproduction in any medium or format, as long as you give appropriate credit to the original author(s) and the source, provide a link to the Creative Commons licence, and indicate if changes were made. The images or other third party material in this article are included in the article's Creative Commons licence, unless indicated otherwise in a credit line to the material. If material is not included in the article's Creative Commons licence and your intended use is not permitted by statutory regulation or exceeds the permitted use, you will need to obtain permission directly from the copyright holder. To view a copy of this licence, visit http://creativecommons.org/licenses/by/4.0/.

\section{References}

Ajalloeian R, Lashkaripour GR (2000) Strength anisotropies in mudrocks. Bull Eng Geol Environ 59:195-199. https://doi.org/ 10.1007/s100640000055

Al-Harthi AA (1998) Effect of planar structures on the anisotropy of Ranyah sandstone Saudi Arabia. Eng Geol 50:49-57. https://doi. org/10.1016/S0013-7952(97)00081-1

Altindag R (2012) Correlation between P-wave velocity and some mechanical properties for sedimentary rocks. J S Afr Inst Min Metal 112:229-237

Bhuiyan MH, Holt RM, Fjaer E (2013) Anisotropic parameters of dry and saturated sand under stress, SEG Annual Meeting, Houston, pp 2836-2840

Budiansky B, O’Connell RJ (1976) Elastic moduli of a cracked solid. Int J Solids Struct 12:81-97. https://doi.org/10.1016/00207683(76)90044-5

Butel N, Hossack A, Kizil MS (2014) Prediction of in situ rock strength using sonic velocity, 14th Coal Operator's Conference, University of Wollongong, 89-102

Chang Ch, Zoback MD, Khaksar A (2006) Empirical relations between rock strength and physical properties in sedimentary rocks. J Petrol Sci Eng 51:223-237. https://doi.org/10.1016/j.petrol.2006.01. 003

Chen H, Hu Z-Y (2001) A preliminary study on the relationship between engineering properties and uniaxial compressive strength of weak sandstones. West Pac Earth Sci 1:297-338

Fjaer E, Holt RM, Horsrud P, Raaen AM, Rines R (2008) Petroleum related rock mechanics. Elsevier Science Publications, Amsterdam

Gegenhuber N, Kienler M (2017) Improved petrographic coded model and its evaluation to determine a thermal conductivity log. Acta Geophys 65:103-118. https://doi.org/10.1007/s11600-017-0010-4

Gegenhuber N, Steiner-Luckabauer C (2012) Vp/Vs Automatic Picking of Ultrasonic Measurements and their Correlation of Petrographic Coded Carbonates from Austria, 74th EAGE Conference \& Exhibition, Copenhagen.
Gegenhuber N, Schifko Th, Pittino G (2017) Petrographic coded model concept for the correlation between geomechanical and elastic properties and its application on log data. Austrian J Earth Sci 110(1):101108. https://doi.org/10.17738/ajes.2017.0007

Horsrud P (2001) Estimating mechanical properties of shale from empirical correlations. SPE Drill Complet 16:68-73. https://doi.org/10.2118/ 56017-PA

Jabbar MA (2011) Correlations of point load index and pulse velocity with the uniaxial compressive strength for rocks. J Eng 4(17):992-1006

Jiang J, Sun J-Z (2011) Comparative study of static and dynamic parameters of rock for the Xishan Rock Cliff Statue. J Zhejiang Univ Sci A 12:771-781. https://doi.org/10.1631/jzus.A1100003

Karakul H, Ulusay R, Isik NS (2010) Empirical models and numerical analysis for assessing strength anisotropy based on block punch index and uniaxial compression tests. Int J Rock Mech Min Sci 47:657-665. https://doi.org/10.1016/j.ijrmms.2010.03.006

Karami, M., Abrah, B., Dayani, S., Framarzi, L. and Nik, M.G., 2012, Empirical Correlations between Static and Dynamic Properties of intact rock. 7th Asian Rock Mechanics Symposium, Seoul, South Korea.

King MS (1983) Static and dynamic elastic properties of rocks from the Canadian Shield. Int J Rock Mech Min Sci 20(5):237-241. https://doi. org/10.1016/0148-9062(83)90004-9

Memarian H (2006) Prediction of mechanical parameters of rock, using shear wave travel time, Geomodel 2006 - 8th EAGE science and applied research conference on oil and gas geological exploration and development, cp-218-00113, doi: https://doi.org/10.3997/2214-4609. 201404029.

Mody FK, Tare U, Wang GG (2008) Application of Geomechanics Technology in Borehole Stability Reduces Well Construction Costs, ARMA 08-25542nd US Rock Mechanics Symposium and 2nd U.S.Canada Rock Mechanics Symposium, San Francisco.

Najibi AR, Ghafoori M, Lashkaripour GR, Asef MR (2015) Empirical relations between strength and static and dynamic elastic properties of Asmari and Sarvak limestone, two main oil reservoirs in Iran. J Petrol Sci Eng 126:78-82. https://doi.org/10.1016/j.petrol.2014.12.010

Nasseri MHB, Rao KS, Ramamurthy T (2003) Anisotropic strength and deformational behaviour of Himalayan schists. Int J Rock Mech Min Sci 40:3-23. https://doi.org/10.1016/S1365-1609(02)00103-X

Nes OM, Fajer E, Tronvoll J, Kristianse TG, Horsrund P (2005) Drilling Time reduction through an integrated rock mechanics analysis, SPE92531-MS, SPE/IADC, Drilling Conference, Amsterdam, doi: https:// doi.org/10.2118/92531-MS

Nygaard R, Hareland G (2007) Application of rock strength in drilling evaluation, SPE 106573-MS, SPE Latin American and Caribbean Petroleum Engineering Conference held in Buenos Aires, Argentina.

Oyler DC, Mark CH, Molinda GM (2008) Correlation of Sonic Travel Time to the Uniaxial Compressive Strength of U.S. Coal Measure Rocks, International Conference on Ground Control in Mining.

Pittino G, Gegenhuber N, Reiter F, Fröhlich R (2015) Axiale Prüfkörperdurchschallung während einaxialer Druckversuche. Berg- und Hüttenmännische Monatshefte 160:565-571. https://doi.org/10.1007/ s00501-015-0423-9

Saroglou H, Marinos P, Tsiambaos G (2004) The anisotropic nature of selected metamorphic rocks from Greece. J S Afr Inst Min Metal 217-222.

Schoen JH (2015) Physical properties of rocks-fundamentals and principles of petrophysics. Elsevier, Pergamon, p 512

Tokle K, Horsrund P, Bratli RK (1986) Prediction Uniaxial compressive strength from log parameters, SPE 15645-MS, SPE Annual Technical Conference and Exhibition, New Orleans, Louisiana, doi: https://doi. org/10.2118/15645-MS

van Heerden WL (1987) General Relations between static and dynamic moduli of rocks. Int J Rock Mech Min Sci Geomech 24:381-385. https://doi.org/10.1016/0148-9062(87)92262-5 